\title{
Digital PCR for direct quantification of viruses without DNA extraction
}

\author{
Jernej Pavšič $^{1,2}$ - Jana Žel ${ }^{1}$ Mojca Milavec ${ }^{1}$
}

Received: 31 August 2015 /Revised: 2 October 2015 / Accepted: 8 October 2015 / Published online: 19 October 2015

(C) The Author(s) 2015. This article is published with open access at Springerlink.com

\begin{abstract}
DNA extraction before amplification is considered an essential step for quantification of viral DNA using realtime PCR (qPCR). However, this can directly affect the final measurements due to variable DNA yields and removal of inhibitors, which leads to increased inter-laboratory variability of qPCR measurements and reduced agreement on viral loads. Digital PCR (dPCR) might be an advantageous methodology for the measurement of virus concentrations, as it does not depend on any calibration material and it has higher tolerance to inhibitors. DNA quantification without an extraction step (i.e. direct quantification) was performed here using $\mathrm{dPCR}$ and two different human cytomegalovirus whole-virus materials. Two dPCR platforms were used for this direct quantification of the viral DNA, and these were compared with quantification of the extracted viral DNA in terms of yield and variability. Direct quantification of both whole-virus materials present in simple matrices like cell lysate or Tris- $\mathrm{HCl}$ buffer provided repeatable measurements of virus concentrations that were probably in closer agreement with the actual viral load than when estimated through quantification of the extracted DNA. Direct dPCR quantification of other viruses, reference materials and clinically relevant matrices is now needed to show the full versatility of this very promising and cost-efficient development in virus quantification.
\end{abstract}

Jernej Pavšič

jernej.pavsic@nib.si

1 Department of Biotechnology and Systems Biology, National Institute of Biology, Večna pot 111, 1000 Ljubljana, Slovenia

2 Jožef Stefan International Postgraduate School, Jamova cesta 39, 1000 Ljubljana, Slovenia
Keywords Digital PCR $\cdot$ Molecular diagnostics $\cdot$ Direct quantification $\cdot$ Viruses $\cdot$ Virus reference materials $\cdot$ Human cytomegalovirus

\begin{tabular}{|c|c|}
\hline \multicolumn{2}{|c|}{ Abbreviations } \\
\hline $\mathrm{Cq}$ & $\begin{array}{l}\text { Quantification cycle in real-time polymerase } \\
\text { chain reaction }\end{array}$ \\
\hline $\mathrm{CV}$ & Coefficient of variability \\
\hline dPCR & Digital polymerase chain reaction \\
\hline EDTA & Ethylenediaminetetraacetic acid \\
\hline HCMV & Human cytomegalovirus \\
\hline INSTAND & $\begin{array}{l}\text { Society for Promoting Quality Assurance in } \\
\text { Medical Laboratories }\end{array}$ \\
\hline IU & International units \\
\hline NIBSC & $\begin{array}{l}\text { National Institute for Biological Standards and } \\
\text { Control }\end{array}$ \\
\hline PBS & Phosphate-buffered saline \\
\hline qPCR & Real-time polymerase chain reaction \\
\hline UL54 & $\begin{array}{l}\text { DNA polymerase gene of the human } \\
\text { cytomegalovirus }\end{array}$ \\
\hline WHO & World Health Organization \\
\hline
\end{tabular}

\section{Introduction}

Real-time PCR (qPCR) is a very sensitive and specific method for quantification of DNA copies, and it is therefore used for a range of clinical applications in the detection and quantification of viruses [1]. DNA extraction before amplification is considered an essential step for the measurement of viral DNA, as it releases the DNA from the capsid and eliminates any PCR-inhibitory substances that are initially present in the matrix $[1,2]$. However, different extraction kits provide different amounts of DNA and remove varying amounts of 
inhibitory substances, consequently reducing agreement on viral loads and hampering inter-laboratory comparability of data $[3,4]$.

Whole-virus reference materials for several viruses have been developed to normalise this quantification variability caused by DNA extraction and suboptimal qPCR assay efficiencies, and therefore to improve comparability of viral-load measurements between laboratories [5]. The viral loads of these reference materials are assigned in terms of the mean qPCR data collected across participants in collaborative studies, and they are expressed as DNA copies (cp)/millilitre or in international units (IU)/millilitre [6, 7]. Consequently, the actual virus concentrations of reference materials remain unknown due to the variable performances of DNA extraction kits and the drawbacks related to relative quantification using qPCR, such as suboptimal commutability of calibration material and variable assay efficiencies $[2,8]$.

Digital PCR (dPCR) is a new PCR-based technology that has already been successfully used for sensitive and reproducible quantification of several different viruses [9]. As it allows robust and precise quantification of nucleic acid copies without the need for any calibration curves and with higher resistance to inhibition [10], dPCR might be more appropriate for quantification of viral loads. However, dPCR is still susceptible to errors caused by DNA extraction, such as variable and suboptimal DNA yields [10].

The two most commonly used dPCR platforms are the QX100 ${ }^{\mathrm{TM}}$ Droplet Digital ${ }^{\mathrm{TM}}$ PCR system (Bio-Rad Laboratories) and the Biomark ${ }^{\mathrm{TM}} \mathrm{HD}$ system (Fluidigm), and these were used here for direct quantification of two whole-virus materials of human cytomegalovirus (HCMV), without the use of DNA extraction. Measurement of the extracted DNA was also carried out to provide a comparison with direct quantification, to define the potential benefits of this novel dPCR approach.

\section{Materials and methods}

\section{Whole-virus materials}

The 1st WHO International Standard for Human Cytomegalovirus for Nucleic Acid Amplification Techniques (National Institute for Biological Standards and Control [NIBSC], code 09/162; 'WHO material') [6] was purchased from the manufacturer and stored at $-20{ }^{\circ} \mathrm{C}$. The $\mathrm{WHO}$ material was in $10 \mathrm{mM}$ Tris- $\mathrm{HCl}$ buffer ( $\mathrm{pH} 7.4)$ and $0.5 \%$ human serum albumin. In the collaborative study of several laboratories using qPCR, the WHO material had been assigned a mean HCMV concentration of $5 \times 10^{6} \mathrm{cp} / \mathrm{mL}$, which was later transformed by the manufacturer into $5 \times 10^{6} \mathrm{IU} / \mathrm{mL}$. Samples no. 365029 , no. 365030 and no. 365032 from the Society for Promoting Quality Assurance in Medical Laboratories
(INSTAND) [7] were kindly provided by Heinz Zeichhardt and Hans-Peter Grunert, and were stored at $-20{ }^{\circ} \mathrm{C}$. The INSTAND materials were in differently diluted lysates from MRC-5 cell cultures infected with HCMV. The final nominal HCMV concentrations of the INSTAND materials, which were each derived from the consensus value from INSTAND Target Value Laboratories using qPCR, were $77,000 \mathrm{cp} / \mathrm{mL}$ for sample no. 365029 and $20,000 \mathrm{cp} / \mathrm{mL}$ for sample no. 365032 , with sample no. 365030 serving as a negative control.

\section{Preparation of materials for DNA extraction and direct quantification}

Prior to the DNA extraction and direct quantification, the WHO and INSTAND materials were initially resuspended in $1 \mathrm{~mL}$ double-distilled water to reach the nominal concentrations provided by the manufacturers $\left(5 \times 10^{6} \mathrm{IU} / \mathrm{mL}\right.$ for the WHO material, $77,000 \mathrm{cp} / \mathrm{mL}$ for INSTAND sample no. 365029 and $20,000 \mathrm{cp} / \mathrm{mL}$ for INSTAND sample no. 365032). To compare the performances of the direct quantification with those of the extracted DNA across a wide dynamic range, the WHO material was volumetrically diluted $1 \times, 10 \times$ and $100 \times$ in double-distilled water, for nominal HCMV concentrations of $5 \times 10^{6}, 5 \times 10^{5}$ and $5 \times 10^{4} \mathrm{IU} / \mathrm{mL}$. The INSTAND samples were not diluted. All of the aliquots of both of these materials were kept at $4{ }^{\circ} \mathrm{C}$ and used within $24 \mathrm{~h}$, for both the DNA extraction and the direct quantification using dPCR.

\section{DNA extraction}

Before DNA extraction of the WHO material, the samples diluted $1 \times, 10 \times$ and $100 \times$ in double-distilled water were volumetrically diluted a further $5 \times$ either in Acrometrix ${ }^{\circledR}$ EDTA Plasma Dilution Matrix (Life Technologies, USA), to mimic a clinical matrix, or in phosphate-buffered saline (PBS), $\mathrm{pH} 7.4$ (137 mM NaCl, $2.7 \mathrm{mM} \mathrm{KCl}, 8 \mathrm{mM} \mathrm{Na} 2 \mathrm{HPO}_{4}, 2 \mathrm{mM}$ $\mathrm{KH}_{2} \mathrm{PO}_{4}$ ). Consequently, $5 \times, 50 \times$ and $500 \times$ WHO sample dilutions reached nominal HCMV concentrations of $1 \times 10^{6}$, $1 \times 10^{5}$ and $1 \times 10^{4} \mathrm{IU} / \mathrm{mL}$. Before DNA extraction, the INSTAND samples were not diluted in any matrix, and therefore, their nominal HCMV concentration remained the same as above for the direct quantification. The DNA extractions were performed using High Pure Viral Nucleic Acid kits (Roche), which we have previously defined as the most efficient manual extraction method in an assessment of three commercial DNA extraction methods from different manufacturers (our unpublished data). All of the DNA extractions were carried out in triplicate, according to the manufacturer protocol. The eluted DNA was stored at $4{ }^{\circ} \mathrm{C}$ and analysed using dPCR within $24 \mathrm{~h}$. 


\section{Preparation of WHO materials for direct virus quantification from human plasma}

To directly quantify samples containing a clinically relevant matrix, the $1 \times$ WHO material was volumetrically diluted an additional $10 \times$ in $100,33.3,11.1$ and $3.7 \%$ Acrometrix $^{\circledR}$ EDTA Plasma Dilution Matrix (Life Technologies, USA), which thus resulted in 90, 30, 10 and $3.3 \%(v / v)$ human plasma in these samples. The initial dilutions of human plasma were performed volumetrically in double-distilled water. Each of these samples was then directly transferred to one or both of the APCR platforms to perform the direct virus quantification.

\section{Copy number measurement of extracted and non-extracted viral DNA using dPCR}

For the copy number measurements of the extracted DNA and directly from the whole viruses, the QX100 and Biomark dPCR platforms were used. PCR assays that targeted the DNA polymerase gene of the human cytomegalovirus (UL54) of the HCMV genome were performed on both of these dPCR platforms using $600 \mathrm{nM}$ primers and $200 \mathrm{nM}$ FAM-BHQ1 hydrolysis probes [11]. The cycling conditions for both of these dPCR platforms were $2 \mathrm{~min}$ at $50^{\circ} \mathrm{C}, 10 \mathrm{~min}$ at $95^{\circ} \mathrm{C}$, and 45 cycles of $15 \mathrm{~s}$ at $95^{\circ} \mathrm{C}$ and $1 \mathrm{~min}$ at $60^{\circ} \mathrm{C}$. For the last step on the QX100 system, $10 \mathrm{~min}$ at $98^{\circ} \mathrm{C}$ was added.

On the QX100 system, the $20-\mu \mathrm{L}$ reaction volumes were composed of $10 \mu \mathrm{L} 2 \times$ Master Mix (ddPCR ${ }^{\mathrm{TM}}$ supermix for probes; Bio-Rad), $1 \mu \mathrm{L}$ UL54 PCR assay, $1 \mu \mathrm{L}$ doubledistilled water and $8 \mu \mathrm{L}$ sample. To reduce the variability caused by pipetting of these small volumes of reaction components, a large volume of the reaction mix was initially prepared in a single tube, which was then distributed into several tubes as $12 \mu \mathrm{L}$ reaction mix. The samples for direct $\mathrm{dPCR}$ quantification were analysed in triplicate and were separately added to the $12-\mu \mathrm{L}$ reaction mix, while the DNA extraction triplicates were each analysed in a single reaction, to maintain equal numbers of observations for both of these quantification approaches and to facilitate the statistical analysis. Data analysis was carried out using the QuantaSoft Analysis software, version 1.3.2.0 (Bio-Rad). Manually determined thresholds allowed simple distinction between positive and negative droplets and were placed at the amplitudes between 1500 and 2500, with the exception of directly quantified INSTAND samples, where the thresholds were determined at the amplitude of 6000, due to higher base fluorescence of the negative droplets. Only reactions with accepted droplet counts above 10,000 were considered. The droplet volume of $0.834 \mu \mathrm{L}$ was taken into account when calculating the DNA copy numbers in the samples [12].

For the Biomark system with the WHO material, $2.1 \mu \mathrm{L}$ of the extracted and non-extracted, and non-diluted and $10 \times$ - diluted, samples were analysed on qdPCR $37 \mathrm{~K}^{\mathrm{TM}}$ Integrated Fluidic Circuits using 6- $\mu \mathrm{L}$ reactions comprising $1.5 \mu \mathrm{L} 4 \times$ TaqMan ${ }^{\circledR}$ Fast Virus 1-Step Master Mix (Applied Biosystems), $0.3 \mu \mathrm{L}$ UL54 PCR assay, $0.6 \mu \mathrm{L}$ 20× GE Sample Loading Reagent (Fluidigm) and $1.5 \mu \mathrm{L}$ double-distilled water. Due to the lower nominal virus concentrations for INSTAND sample no. $365029,4 \mu \mathrm{L}$ of the extracted and non-extracted samples was tested in $10-\mu \mathrm{L}$ reactions on 12.765 Digital Array ${ }^{\mathrm{TM}}$ Integrated Fluidic Circuits. These reactions were carried out with $2.5 \mu \mathrm{L} 4 \times \mathrm{TaqMan}^{\circledR}$ Fast Virus 1-Step Master Mix (Applied Biosystems), $0.5 \mu \mathrm{L}$ UL54 PCR assay, $0.5 \mu \mathrm{L} 20 \times$ GE Sample Loading Reagent (Fluidigm) and $2.5 \mu \mathrm{L}$ double-distilled water. For each array, a large volume of reaction mix was initially prepared in a single tube, followed by its distribution into several tubes containing either $3.9 \mu \mathrm{L}$ reaction mix $(6-\mu \mathrm{L}$ reaction) or $6 \mu \mathrm{L}$ reaction mix (10- $\mu \mathrm{L}$ reaction). The samples for direct quantification were analysed in duplicate and were separately added to the reaction mix. For the DNA extraction triplicates, only two randomly selected triplicates were analysed each in a single reaction, to provide equal numbers of observations as for the direct quantification, and therefore to allow better comparisons of variability between these two approaches. Data analysis was carried out using the Biomark ${ }^{\mathrm{TM}}$ HD Data Collection Software, v3.1.4 (Fluidigm), with manual determination of the fluorescence threshold, the accepted quantification cycle in real-time polymerase chain reaction $(\mathrm{Cq})$ range $(15-45 \mathrm{Cq})$ and the quality threshold (0.2).

\section{Statistical analysis}

The coefficient of variability (CV) for the replicates was calculated using the formula:

$\mathrm{CV}=\frac{\text { standard deviation }}{\text { mean concentration }}$

Student's $t$ tests (two tailed, two-sample equal variance) were used in Microsoft Excel 2007 to determine the statistical significances of the differences between the different sets of measurements.

\section{Results}

\section{Comparison of the direct quantification of DNA from whole viruses and quantification of extracted viral DNA}

Both quantification approaches were assessed using both the QX100 and Biomark systems and using the WHO material and INSTAND samples. On the QX100 system that used direct quantification of the viral DNA, the DNA copy number 
measurements were 18 and $35 \%$ higher in comparison to the quantification of the extracted DNA from human plasma and PBS buffer, respectively (Fig. 1). Even greater differences were seen using the Biomark system, with 26 and $53 \%$ higher DNA concentrations observed, respectively. The same pattern was observed with INSTAND sample no. 365032 analysed using the QX100 system and INSTAND sample no. 365029 analysed using the Biomark system, where 39 and $35 \%$ higher DNA concentrations were measured, respectively, using direct quantification (Fig. 2). In contrast, when INSTAND sample no. 365029 was analysed, using the QX100 system, no statistically significant differences were found between either of the quantification approaches.

\section{Comparison of DNA extractions from human plasma and PBS}

Viral DNA was extracted from $1 \times, 10 \times$ and $100 \times$ dilutions of the WHO material that were then further diluted $5 \times$ in human plasma or PBS. On the QX100 system, extraction of the viral DNA from human plasma was more efficient compared with the extraction from PBS buffer, as the mean measured copy numbers were $15 \%$ higher with the human plasma $(p<0.01)$ (Fig. 1). On the contrary, on the Biomark system, although $22 \%$ higher mean measured copy numbers were seen for human plasma versus PBS, this difference did not reach statistical significance.

\section{Agreement between the dPCR platforms}

No statistically significant differences were seen between the QX100 and Biomark systems for the mean measured copy numbers of the WHO material and INSTAND samples (Figs. 1 and 2), with the exception of direct quantification of INSTAND sample no. 365029, where the Biomark system showed $47 \%$ higher mean measured copy numbers compared to the QX100 system $(p<0.01)$. However, the lack of statistically significant differences should be taken with caution here due to the small number of measurements performed with the WHO material on the Biomark system and with the INSTAND sample on both of the dPCR platforms.

\section{Assessment of variability}

Direct quantification of the DNA derived from the whole virus particles was equally repeatable, or even more repeatable, than that of the extracted DNA, independent of the dPCR platform used or the material used (Tables 1 and 2). Additionally, the CVs using direct quantification did not exceed $10 \%$, while the quantification of the extracted DNA from the PBS buffer had CVs generally $>10 \%$. On the Biomark system using extracted DNA from samples in PBS, higher variability was observed in comparison to that on the QX100 system.

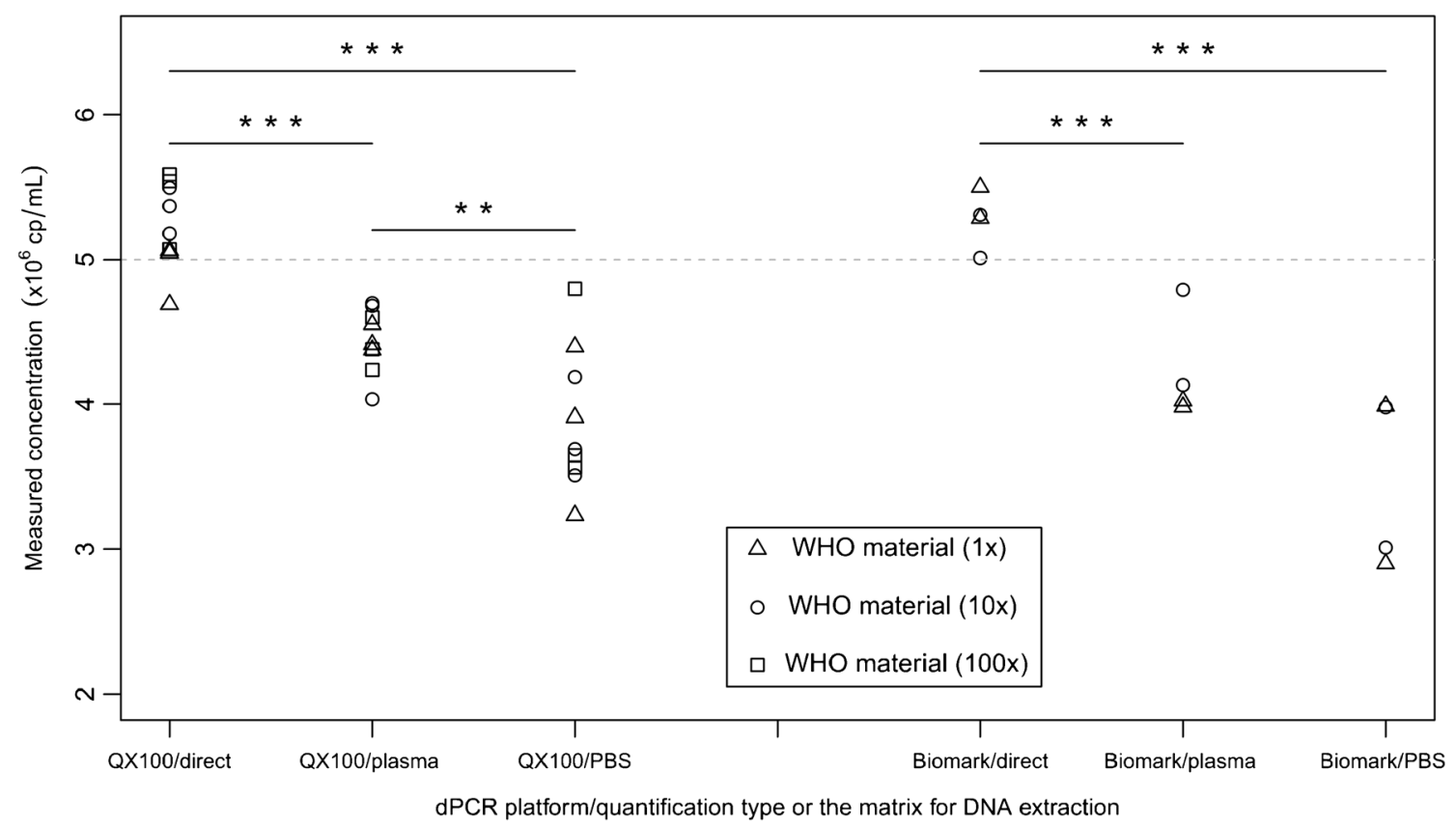

Fig. 1 Comparison of direct quantification of DNA from whole-virus materials and quantification of extracted viral DNA using the WHO material on each of the dPCR platforms. The nominal predicted concentration is shown as a grey dotted line. Each data point represents a single dPCR measurement. For the DNA extraction, an additional $5 \times$ dilution in human plasma or PBS buffer was performed for each dilution of the WHO material. ${ }^{* * *} p<0.001$ and $* * p<0.01$ between the two groups for DNA copy numbers (Student's $t$ tests) 


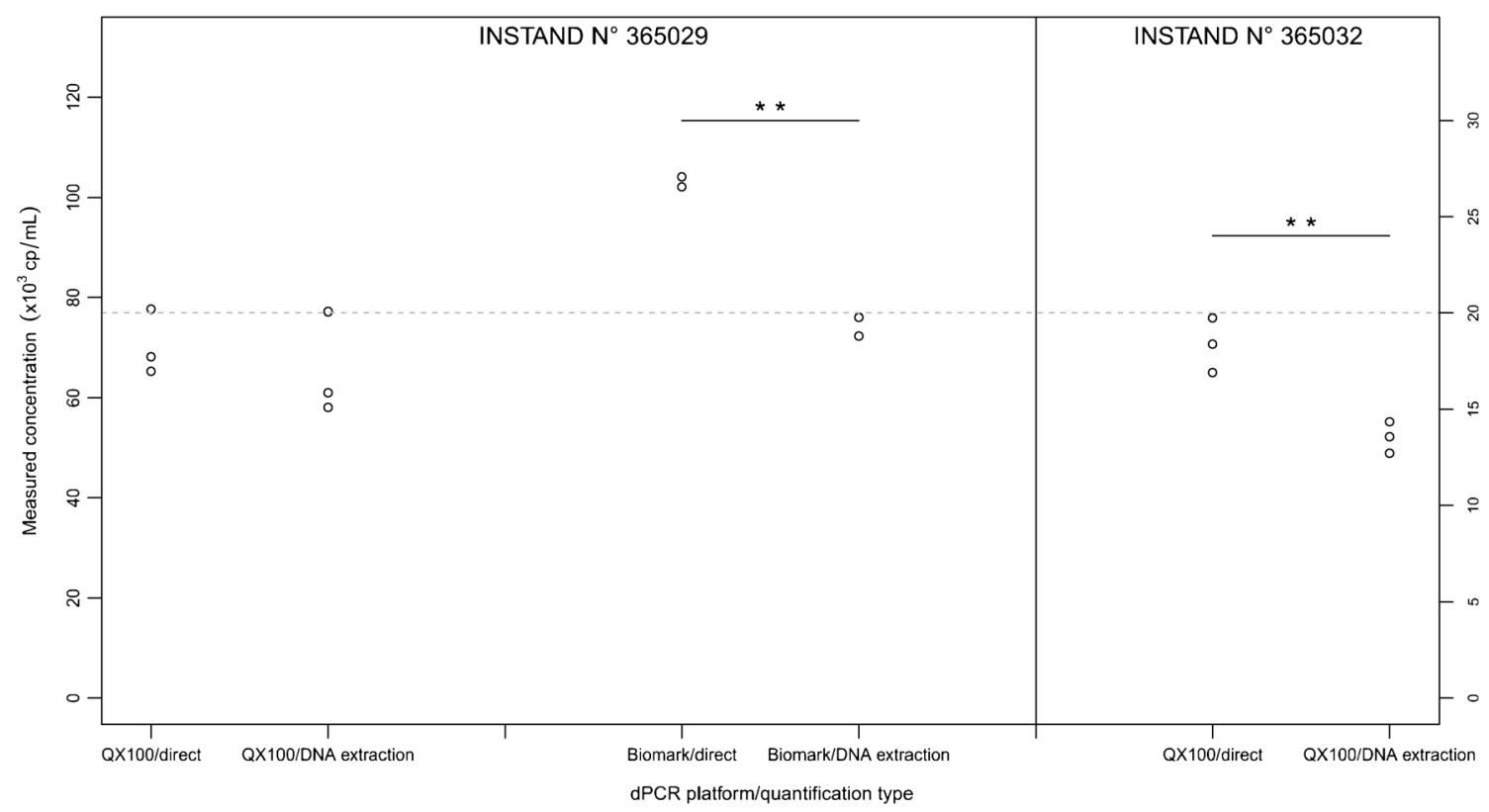

Fig. 2 Comparison of copy number measurements between the direct quantification of DNA from whole viruses and the quantification of extracted viral DNA using the INSTAND material on each of the dPCR

\section{Direct quantification from human plasma}

Various effects on the direct quantification were seen for the samples with different human plasma concentrations (Fig. 3). For the samples with 3.3 and $10 \%(v / v)$ human plasma, the measured copy numbers were only 31 and $4 \%$ of the nominal concentrations, respectively. For duplicates with $3.3 \%(v / v)$ human plasma, the $\mathrm{CV}$ value was $5 \%$, while for duplicates with $10 \%(v / v)$ human plasma, the $\mathrm{CV}$ value was $11 \%$. On platforms. The nominal predicted concentration is shown as a grey dotted line. Each data point represents a single dPCR measurement. ${ }^{* *} p<0.01$ between the two groups for DNA copy numbers (Student's $t$ tests)
Table 1 Variability of the direct quantification of DNA from whole viruses and quantification of extracted viral DNA using different materials on the QX100 ${ }^{\mathrm{TM}}$ Droplet Digital ${ }^{\mathrm{TM}}$ PCR system. DNA the other hand, no amplification was observed with samples containing $\geq 30 \%(v / v)$ human plasma. Additionally, negative effects on the droplets were observed, as only around $4600 \pm$ 200 droplets and $8300 \pm 900$ droplets were acceptable for analysis by the software for the samples with 30 and $90 \%(v / v)$ human plasma, respectively. In contrast, there was no such influence with the lowest two concentrations of human plasma, for which around 16,000 droplets were analysed. The inclusion of human plasma influenced the intensity of the

extractions were performed using either WHO material spiked with human plasma and PBS or INSTAND samples with viruses in cell lysates

\begin{tabular}{|c|c|c|c|c|c|c|c|c|c|c|}
\hline \multirow[t]{3}{*}{ Material } & \multicolumn{3}{|l|}{ Direct quantification } & \multicolumn{7}{|c|}{ Quantification of extracted DNA } \\
\hline & \multirow{2}{*}{$\begin{array}{l}\text { Nominal viral load } \\
\text { (IU/mL or } \mathrm{cp} / \mathrm{mL})\end{array}$} & \multirow[t]{2}{*}{$\lambda^{\mathrm{b}}$} & \multirow[t]{2}{*}{$\mathrm{CV}^{\mathrm{c}}(\%)$} & \multirow{2}{*}{$\begin{array}{l}\text { Nominal viral load } \\
\text { (IU/mL or } \mathrm{cp} / \mathrm{mL} \text { ) }\end{array}$} & \multicolumn{2}{|c|}{ Human plasma } & \multicolumn{2}{|l|}{ PBS } & \multicolumn{2}{|c|}{ Cell lysate } \\
\hline & & & & & $\lambda^{\mathrm{b}}$ & $\mathrm{CV}^{\mathrm{c}}(\%)$ & $\lambda^{\mathrm{b}}$ & $\mathrm{CV}^{\mathrm{c}}(\%)$ & $\lambda^{\mathrm{b}}$ & $\mathrm{CV}^{\mathrm{c}}(\%)$ \\
\hline WHO $(1 \times)^{\mathrm{d}}$ & $5 \times 10^{6}$ & 1.6 & 4 & $1 \times 10^{6}$ & 1.18 & 2 & 1 & 15 & - & - \\
\hline WHO $(10 \times)^{d}$ & $5 \times 10^{5}$ & 0.17 & 3 & $1 \times 10^{5}$ & 0.12 & 8 & 0.1 & 9 & - & - \\
\hline WHO $(100 \times)^{\mathrm{d}}$ & $5 \times 10^{4}$ & 0.017 & 5 & $1 \times 10^{4}$ & 0.01 & 8 & 0.01 & 17 & - & - \\
\hline No. $365029^{\mathrm{e}}$ & $7.7 \times 10^{4}$ & 0.022 & 9 & $7.7 \times 10^{4}$ & - & - & - & - & 0.08 & 20 \\
\hline No. $365032^{\mathrm{e}}$ & $2 \times 10^{4}$ & 0.006 & 8 & $2 \times 10^{4}$ & - & - & - & - & 0.17 & 10 \\
\hline
\end{tabular}

${ }^{a}$ Nominal viral concentration of the sample before quantification, based on the nominal concentration of each of the whole virus materials and their volumetric dilutions in double-distilled water, human plasma or PBS

${ }^{\mathrm{b}}$ Mean DNA copy number per partition

${ }^{\mathrm{c}}$ Coefficient of variability that was calculated on the basis of three measurements $(n=3)$ on the QX100 system

${ }^{\mathrm{d}}$ First WHO International Standard for Human Cytomegalovirus for Nucleic Acid Amplification Techniques [6]

${ }^{\mathrm{e}}$ INSTAND external quality assurance scheme sample [7] 
Table 2 Variability of the direct quantification of DNA from whole viruses and quantification of extracted viral DNA using different materials on the Biomark ${ }^{\mathrm{TM}} \mathrm{HD}$ system. DNA extractions were performed using either WHO material spiked with human plasma or
PBS, or INSTAND samples with viruses in cell lysates. WHO $(100 \times)$ material and INSTAND sample no. 365032 were not analysed due to inadequate nominal DNA concentrations ( $<40$ copies/effective reaction size)

\begin{tabular}{|c|c|c|c|c|c|c|c|c|c|c|}
\hline \multirow[t]{3}{*}{ Material } & \multicolumn{3}{|l|}{ Direct quantification } & \multicolumn{7}{|c|}{ Quantification of extracted DNA } \\
\hline & \multirow{2}{*}{$\begin{array}{l}\text { Nominal viral load } \\
\text { (IU/mL or } \mathrm{cp} / \mathrm{mL} \text { ) }\end{array}$} & \multirow[t]{2}{*}{$\lambda^{\mathrm{b}}$} & \multirow[t]{2}{*}{$\mathrm{CV}^{\mathrm{c}}(\%)$} & \multirow{2}{*}{$\begin{array}{l}\text { Nominal viral load } \\
\text { (IU/mL or } \mathrm{cp} / \mathrm{mL})\end{array}$} & \multicolumn{2}{|c|}{ Human plasma } & \multicolumn{2}{|c|}{ PBS } & \multicolumn{2}{|c|}{ Cell lysate } \\
\hline & & & & & $\lambda^{\mathrm{b}}$ & $\mathrm{CV}^{\mathrm{c}}(\%)$ & $\lambda^{\mathrm{b}}$ & $\mathrm{CV}^{\mathrm{c}}(\%)$ & $\lambda^{\mathrm{b}}$ & $\mathrm{CV}^{\mathrm{c}}(\%)$ \\
\hline WHO $(1 \times)^{\mathrm{d}}$ & $5 \times 10^{6}$ & 1.6 & 2 & $1 \times 10^{6}$ & 1.18 & 3 & 1 & 25 & - & - \\
\hline WHO $(10 \times)^{\mathrm{d}}$ & $5 \times 10^{5}$ & 0.15 & 5 & $1 \times 10^{5}$ & 0.12 & 16 & 0.1 & 29 & - & - \\
\hline No. $365029^{\mathrm{e}}$ & $7.7 \times 10^{4}$ & 0.25 & 0 & $7.7 \times 10^{4}$ & - & - & - & - & 0.08 & 5 \\
\hline
\end{tabular}

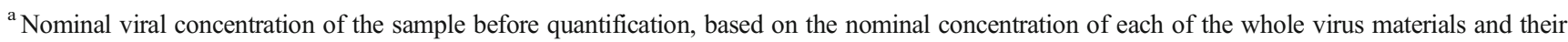
volumetric dilutions in double-distilled water, human plasma or PBS

${ }^{\mathrm{b}}$ Mean DNA copy number per partition

${ }^{\mathrm{c}}$ Coefficient of variability that was calculated on the basis of two measurements $(n=2)$ on the Biomark system

${ }^{\mathrm{d}}$ First WHO International Standard for Human Cytomegalovirus for Nucleic Acid Amplification Techniques [6]

${ }^{\mathrm{e}}$ INSTAND external quality assurance scheme sample [7]

fluorescence, as in the positive droplets it was inversely proportional to the concentration of the matrix, while the opposite effect was seen for negative droplets.

\section{Discussion}

To the best of our knowledge, this is the first report of direct quantification of DNA derived from whole virus particles performed on two different dPCR platforms. This study indicates that the heat treatment at $95^{\circ} \mathrm{C}$ during dPCR was enough to degrade the HCMV viral coat proteins and to release the viral DNA into the reaction mixture. Although some viruses have already been directly quantified using qPCR without DNA extraction, such as HCMV, hepatitis B virus and human adenovirus [13-15], drawbacks related to the qPCR formats probably hampered the precise and reliable measurements of the actual virus concentrations using this direct quantification approach, such as susceptibility to inhibitory substances and dependence on the calibration material [2]. The commutability of such calibration material with clinical samples would probably represent an additional problem, as the calibration materials do not always behave in the same way as whole-virusderived DNA from different matrices, which can lead to overestimation or underestimation of the DNA in the samples tested [8].

In the present study with the direct quantification approach using whole-virus materials in simple matrices, higher DNA copy numbers were measured compared to those from the extracted DNA, regardless of the dPCR platform used. In contrast to qPCR, dPCR is more resistant to inhibitory effects of different matrices and is not dependent on calibration material and its commutability [10], and thus only minor overestimation and underestimation of the actual DNA copy numbers are expected. Consequently, the differences in the copy number measurements between these approaches are most likely to be due to DNA loss during the DNA extraction. Therefore, it is reasonable to assume that the direct quantification measurements will be in closer agreement with the actual virus concentrations than the quantification of the extracted DNA.

Although in most cases good agreement was observed between the direct virus quantification and the nominal virus values for both of the whole-virus materials, the potential for bias of APCR measurements still needs to be taken into consideration, as the nominal concentrations of each of these materials might not be close to the actual viral load, as they were assigned in collaborative studies using different qPCR assays and extraction kits $[6,7]$. Therefore, it is difficult to determine the levels of agreement between the data based on the measured copy numbers of amplified DNA derived from whole viruses and the actual viral load in the sample or the reference material. As overestimation can occur only when two singlestranded DNA molecules that derive from the same doublestranded DNA are found in two different partitions [10], this is less likely to occur with direct quantification, as the DNA molecules are most likely packed inside the viral capsid at the time of partitioning. On the other hand, special care needs to be taken to define the possible sources of underestimation. In the case of molecular dropout, the DNA template is present but it is not amplified, due to factors that damage the DNA target region or make it less accessible to primers and DNA polymerase $[10,16]$. Due to the presence of viral coat proteins and undiluted matrix, molecular dropout is probably more likely to occur for direct virus quantification than in pure DNA extracts. This phenomenon can be avoided by using 
Fig. 3 Determination of direct quantification of viral DNA from different matrices. The left column represents the direct quantification of the $10 \times \mathrm{WHO}$ reference material in NIBSC buffer (10 mM Tris-HCl, pH 7.4, $0.5 \%$ human serum albumin). The columns on the right represent the $1 \times$ WHO material spiked into different concentrations of human plasma $(3.3,10,30$, and $90 \%$; all $v / v)$, which resulted in a $10 \times$ dilution of the initial material

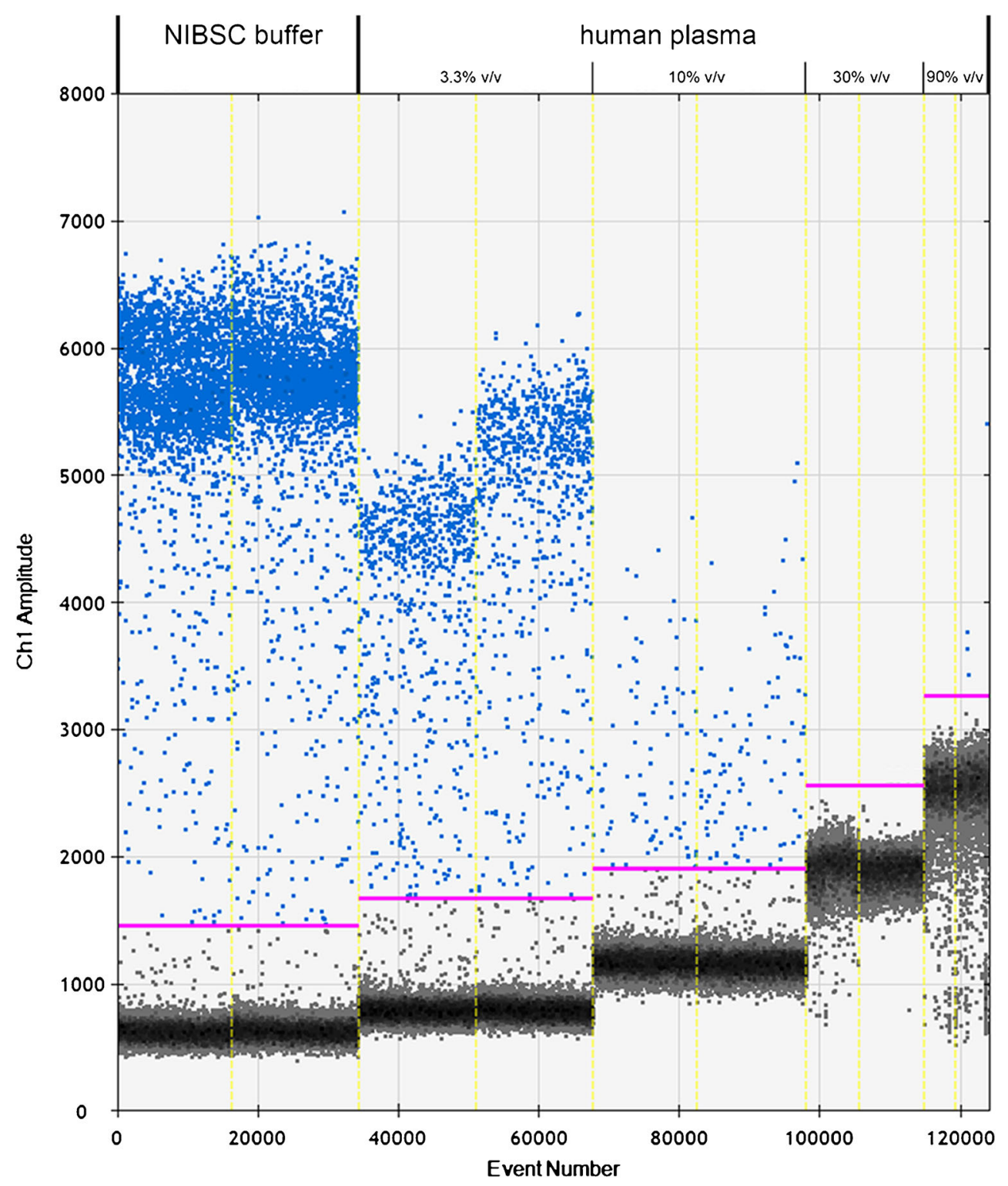

two or more different assays that target various genomic regions on the DNA template, which will increase the probability that at least one region will be accessible and amplifiable [16]. Another possible source of underestimation is a nonhomogeneous distribution of viruses caused by their linking prior to and during partitioning, as some viruses tend to aggregate [15]. As aggregation is dependent on the solution $\mathrm{pH}$ and the concentrations of specific cations and anions [15], various combinations of master mixes and matrices might result in different levels of aggregation. Therefore, the Biomark system can be used for the selection of the master mix composition that shows the highest disturbance of virus aggregation in specific matrices. Additionally, aggregation can potentially be regulated by the addition of cations and anions, or by adjusting the matrix $\mathrm{pH}$. However, no virusvirus complexes have been observed for HCMV, to the best of our knowledge. Another possible factor for underestimation is the presence of dPCR inhibitors, such as human plasma and ethylenediaminetetraacetic acid (EDTA), which is discussed further below.

Although DNA extractions from human plasma on the QX100 system have been found to cause significantly higher DNA extraction yields than DNA extractions from PBS, on the Biomark system no statistical significance was found between these two matrices. However, this lack of statistical significance on the Biomark system might be due to the low number of measurements, as only two dilutions of WHO material were each tested in duplicate $(n=4)$, while on the QX100 system, three dilutions of the WHO material were each tested in triplicate $(n=9)$. Furthermore, as the High Pure Viral Nucleic Acid kits are designed for DNA extraction of viruses from human plasma, serum and whole blood, it appears likely 
that the DNA extractions from human plasma resulted in lower variability and higher DNA extraction yields than those from PBS. It could be speculated that in contrast to PBS, human plasma contains molecules, which in combination with extraction-kit buffers function as DNA carriers or prevent DNA molecules from fragmentation. This finding might indicate that the matrix had an important impact on the final measurements of the extracted DNA copy numbers. The different matrices will probably mainly alter the DNA extraction yields, as unsuccessfully eliminated PCR inhibitors would have only minor effects on the final DNA copy number estimations when APCR is used $[17,18]$. The differences between direct quantification and quantification of extracted DNA in terms of estimated DNA copy numbers might therefore allow assessment of DNA extraction by the evaluation of the matrix influence on the extraction yield. Thus, it appears reasonable to assume that the INSTAND material that comprised lysates of HCMV-infected MRC-5 cell cultures resulted in lower DNA extraction yields than the WHO material in human plasma, as greater differences were seen for the INSTAND material between the two quantification approaches.

Interestingly, equal performances for both of the quantification approaches were observed when INSTAND sample no. 365029 was measured on the QX100 system, in terms of the measured viral DNA copy numbers. As the statistically significant difference between both dPCR platforms was observed only with direct quantification of this particular sample, different matrix/master mix effects can be assumed, leading either to underestimation of the QX100 system or overestimation of the Biomark system. This hypothesis is additionally strengthened as there was no statistically significant difference between either of the dPCR platforms when the extracted DNA from INSTAND sample no. 365029 was measured, with no original matrix present. Furthermore, a $4 \times$ more diluted matrix might explain why no such matrix/master mix effects were seen with direct quantification of INSTAND sample no. 365032 [7]. Overestimation by the Biomark system or underestimation by the QX100 system due to partition volume variations is also not very likely, as no statistically significant differences were seen between these two platforms when measuring the WHO material. Therefore, as for all of the other samples tested on both of the dPCR platforms, statistically significant increases were observed when direct quantification was used instead of when extracted DNA was used; it is more reasonable to assume underestimation by the QX100 system than overestimation by the Biomark system.

In the majority of cases, the repeatability of the direct quantification was not only equal to or better than that for the DNA extracts, but also sometimes even lower than the theoretically predicted variability for both of these dPCR platforms using Poisson distributions [19]. This strongly indicates that the presence of whole viruses and different matrices does not influence the repeatability, while no additional variability is introduced as the DNA extraction step is avoided. Additionally, in the case of the extracted DNA from the WHO material in PBS, the higher variability that was noted with the Biomark system in comparison to that with the QX100 system might be due to the smaller numbers of measurements and/or smaller volumes of the sample input.

Although the chip-based Biomark system and the droplet-based QX100 system have both been shown to be more resilient to a range of inhibitors when compared to qPCR [17, 18], and might therefore be more appropriate for direct quantification from clinically relevant matrices, different inhibitory effects were observed with direct quantification from human plasma. Using the QX100 system, at the higher concentrations of human plasma, the formation of droplets was probably altered, as smaller numbers of droplets were accepted for analysis by the reader. Moreover, at all concentrations of human plasma, higher base fluorescence in the accepted droplets was observed, which might indicate a larger mean volume of the droplets in comparison to those without human plasma. This phenomenon probably correlates with the concentration of human plasma, as the highest base fluorescence was noted in droplets that contained the most concentrated human plasma. Inhibition not only reduced the fluorescence intensity in positive droplets but also hampered the final measurements of the DNA copy numbers. This is in partial agreement with a previous research conducted with the extracted HCMV DNA on the Biomark system, where in the presence of $25 \%(v / v)$ human plasma, there was a very repeatable, approximately $10 \times$ decrease in the DNA copy number measurements [18]. However, more than a $20 \times$ decrease was seen in the present study when $10 \%(v / v)$ human plasma was used, while there was no amplification for samples with $30 \%(v / v)$ and $90 \%(v / v)$ human plasma. The higher degree of inhibition in the present study might be the consequence of the presence of the anticoagulant, as $50 \mathrm{mM} \mathrm{Na}_{2}$ EDTA, to which dPCR is very susceptible [17, 18]. Although EDTA can cause changes of up to $100 \times$ in the measurement of DNA copy numbers on dPCR [18], no such effect was seen for the two pairs of duplicates in the present study, although higher variability might have been detected if more replicates had been analysed. Direct quantification on either dPCR platform did not appear to be suitable for the quantification of HCMV from human plasma due to partial or complete PCR inhibition that resulted in underestimation of DNA copy numbers. However, successful qPCR-based quantification of HCMV from urine samples and hepatitis B from human serum have indicated the potential suitability of direct quantification of HCMV and other viruses from these two clinical matrices [13, 14]. 


\section{Conclusions}

Direct quantification by dPCR is shown here to provide repeatable measurements of viral DNA copy numbers that appear to be in closer agreement with the actual viral load than with either dPCR-based or qPCR-based quantification of extracted DNA. This indicates that direct quantification of whole HCMV DNA using dPCR is a valuable approach for the characterisation of viral reference materials and materials for external quality assurance schemes that are in simple matrices, while unpromising results were obtained using the complex matrix of human plasma. Additionally, this direct quantification might also be appropriate for efficiency assessments of different extraction methods from simple matrices. Further studies using different assays and master mixes can now be performed to characterise and reduce the possible sources of underestimation. Exploration of direct quantification by $\mathrm{dPCR}$ for other viruses, reference materials and clinically relevant matrices is also necessary, to determine the full versatility of this very promising development in virus quantification.

Acknowledgments This study was financially supported by the INFECT MET (the EMRP project; jointly funded by the EMRP participating countries within EURAMET and the European Union) and the Slovenian Research Agency (contract nos. P4-0165 and 1000-13-0105). The QX100 system used in this study was financed by the Metrology Institute of the Republic of Slovenia, with financial support from the European Regional Development Fund. The INSTAND external quality assurance scheme samples were provided through the courtesy of Heinz Zeichhardt, of Charité-University Medicine Berlin, and Hans-Peter Grunert, of Gesellschaft für Biotechnologische Diagnostik mbH, Berlin. The manuscript was edited for scientific language by Christopher Berrie.

\section{Compliance with ethical standards}

Conflict of interest The authors declare that they have no competing interests.

Open Access This article is distributed under the terms of the Creative Commons Attribution 4.0 International License (http:// creativecommons.org/licenses/by/4.0/), which permits unrestricted use, distribution, and reproduction in any medium, provided you give appropriate credit to the original author(s) and the source, provide a link to the Creative Commons license, and indicate if changes were made.

\section{References}

1. Espy MJ, Uhl JR, Sloan LM, Buckwalter SP, Jones MF, Vetter EA, Yao JDC, Wengenack NL, Rosenblatt JE, Cockerill FR III, Smith TF (2006) Real-time PCR in clinical microbiology: applications for routine laboratory testing. Clin Microbiol Rev 19:165-256

2. Bustin SA, Benes V, Garson JA, Hellemans J, Huggett J, Kubista M, Mueller R, Nolan T, Pfaffl MW, Shipley GL, Vandesompele J, Wittwer CT (2009) The MIQE guidelines: minimum information for publication of quantitative real-time PCR experiments. Clin Chem 55:611-622
3. Verheyen J, Kaiser R, Bozic M, Timmen-Wego M, Maier BK, Kessler HH (2012) Extraction of viral nucleic acids: comparison of five automated nucleic acid extraction platforms. J Clin Virol 54: 255-259

4. Hayden RT, Yan X, Wick MT, Rodriguez AB, Xiong X, Ginocchio CC, Mitchell MJ, Caliendo AM (2012) Factors contributing to variability of quantitative viral PCR results in proficiency testing samples: a multivariate analysis. J Clin Microbiol 50:337-345

5. Madej RM, Davis J, Holden MJ, Kwang S, Labourier E, Schneider GJ (2010) International standards and reference materials for quantitative molecular infectious disease testing. J Mol Diagn 12:133143

6. Fryer JF, Heath AB, Anderson R, Minor PD, collaborative study group (2010) Collaborative study to evaluate the proposed 1st WHO International Standard for human cytomegalovirus (HCMV) for nucleic acid amplification (NAT)-based assays. http://apps.who.int/iris/bitstream/10665/70521/1/WHO_BS_10. 2138 eng.pdf?ua $=1$. Accessed 17 July 2014

7. Zeichhardt H, Grunert HP (2012) Final report external quality assessment scheme (EQAS) - March/April 2012 virus genome detection-cytomegalovirus (365) (PCR/NAT-CMV). http://www. instandev.de/uploads/tx nfextinstandpdf/351_Cytomegalovirus March April 2012 EN Homepage Version 20120522.pdf. Accessed 30 Nov 2014

8. Caliendo AM, Shahbazian MD, Schaper C, Ingersoll J, Abdul-Ali D, Boonyaratanakornkit J, Pang X-L, Fox J, Preiksaitis J, Schönbrunner ER (2009) A commutable cytomegalovirus calibrator is required to improve the agreement of viral load values between laboratories. Clin Chem 55:1701-1710

9. Sedlak RH, Jerome KR (2013) Viral diagnostics in the era of digital polymerase chain reaction. Diagn Microbiol Infect Dis 75:1-4

10. Huggett JF, Cowen S, Foy CA (2015) Considerations for digital PCR as an accurate molecular diagnostic tool. Clin Chem 61:79-88

11. Sassenscheidt J, Rohayem J, Illmer T, Bandt D (2006) Detection of beta-herpesviruses in allogenic stem cell recipients by quantitative real-time PCR. J Virol Methods 138:40-48

12. Corbisier P, Pinheiro L, Mazoua S, Kortekaas A-M, Chung PYJ, Gerganova T, Roebben G, Emons H, Emslie K (2015) DNA copy number concentration measured by digital and droplet digital quantitative PCR using certified reference materials. Anal Bioanal Chem 407:1831-1840

13. Kearns AM, Draper B, Wipat W, Turner AJL, Wheeler J, Freeman R (2001) LightCycler-based quantitative PCR for detection of cytomegalovirus in blood, urine, and respiratory samples. J Clin Microbiol 39:2364-2365

14. Cheng Z-J, Hu L-H, Fu W-R, Li Y-R (2007) Rapid quantification of hepatitis B virus DNA by direct real-time PCR from serum without DNA extraction. J Med Microbiol 56:766-771

15. Wong K, Mukherjee B, Kahler AM, Zepp R, Molina M (2012) Influence of inorganic ions on aggregation and adsorption behaviors of human adenovirus. Environ Sci Technol 46:11145-11153

16. Whale AS, Cowen S, Foy CA, Huggett JF (2013) Methods for applying accurate digital PCR analysis on low copy DNA samples. PLoS One 8:e58177. doi:10.1371/journal.pone.0058177

17. Dingle TC, Sedlak RH, Cook L, Jerome KR (2013) Tolerance of droplet-digital PCR vs real-time quantitative PCR to inhibitory substances. Clin Chem 59:1670-1672

18. Nixon G, Garson JA, Grant P, Nastouli E, Foy CA, Huggett JF (2014) A comparative study of sensitivity, linearity and resistance to inhibition of digital and non- digital PCR and LAMP assays for quantification of human cytomegalovirus. Anal Chem 86:43874394

19. Devonshire AS, Honeyborne I, Gutteridge A, Whale AS, Nixon G, Wilson P, Jones G, Mchugh TD, Foy CA, Huggett JF (2015) Highly reproducible absolute quantification of Mycobacterium tuberculosis complex by digital PCR. Anal Chem 87:3706-3713 